\title{
Early-Adult Life Correlates of Personality in Parkinson's Disease
}

\author{
Kelly L. Sullivan ${ }^{\mathrm{a}, \mathrm{b}, \mathrm{d}}$, James A. Mortimer ${ }^{\mathrm{a}}$, Wei Wang ${ }^{\mathrm{a}}$, Theresa A. Zesiewicz \\ H. James Brownlee Jrc ${ }^{\mathrm{c}}$, Amy R. Borenstein ${ }^{\mathrm{a}}$
}

\begin{abstract}
Background: Parkinson's disease (PD) patients have been described as having an introverted, rigid and harm-avoidant personality, which present decades before motor symptoms begin. Previous studies have relied on subjective reports about patients' premorbid personalities. The objectives of this study were to examine current personality profiles of PD patients and to assess how personality indicators of early-adult life correlate with current personality.
\end{abstract}

Methods: Data were collected from 89 PD cases and 99 controls through in-person assessments of current personality characteristics and early-adult life personality indicators based on activities and lifestyle patterns during ages 20 - 35 years. Associations of latent variables representing early-adult activity risks, lifestyle risks and routinization with current personality characteristics were studied using Pearson correlations, partialling out the effects of age, sex and education.

Results: Greater current levels of neuroticism (OR $=1.05(95 \% \mathrm{CI}$ 1.00 - 1.11) ) and harm-avoidance $(\mathrm{OR}=1.07$ (95\% CI $1.00-1.15))$ were evident in cases compared to controls, adjusting for age, sex and education. Significant correlations between early-life indicators and late-life personality characteristics were consistent among cases and controls for associations of early-adult life routinization with current measures of neuroticism (cases: $r=0.33, \mathrm{P}=0.01$; controls: $\mathrm{r}=0.26, \mathrm{P}=0.04$ ), extraversion (cases: $\mathrm{r}=-0.33, \mathrm{P}=0.01$; controls: $\mathrm{r}=-0.33, \mathrm{P}=0.04$ ), novelty-seeking (cases: $\mathrm{r}=-0.33, \mathrm{P}=$

Manuscript accepted for publication June 25, 2014

${ }^{a}$ Department of Epidemiology and Biostatistics, College of Public Health, University of South Florida, Tampa, FL, USA

${ }^{b}$ Department of Neurology, College of Medicine, University of South Florida, Tampa, FL, USA

${ }^{c}$ Department of Family Medicine, College of Medicine, University of South Florida, Tampa, FL, USA

${ }^{\mathrm{d} C}$ Corresponding Author: Kelly Sullivan, University of South Florida, 12901 Bruce B. Downs Blvd., MDC 55, Tampa, FL 33612, USA.

Email: kbarber@health.usf.edu

doi: http://dx.doi.org/10.14740/jnr280w
0.015; controls: $\mathrm{r}=-0.34, \mathrm{P}=0.007$ ) and harm-avoidance (cases: $\mathrm{r}=0.47, \mathrm{P}=0.0003$; controls: $\mathrm{r}=0.45, \mathrm{P}=0.0002)$ and for earlyadult life activity risks with harm-avoidance (cases: $\mathrm{r}=-0.47, \mathrm{P}=$ 0.0004; controls: $\mathrm{r}=-0.42, \mathrm{P}=0.0006$ ).

Conclusion: Current personality profile of PD cases, reflected by higher neuroticism and harm-avoidance, may reflect stable personality traits characterized by greater routinization and lower risktaking in earlier adult life.

Keywords: Novelty-seeking; Routinization; Risk-taking; Premorbid; Risk factors

\section{Introduction}

As early as 1913, a distinct personality type was described in patients with Parkinson's disease (PD) [1]. PD patients have been described as rigid, cautious and introverted [2]. It is biologically plausible that patients with PD may have differences in their personality due to the role of dopamine and the neurophysiology of the reward system of the brain. The dopaminergic nuclei of the brain stem not only are involved in the pathophysiology of motor symptoms [3], but also influence personality [4]. Nevertheless, the evolution of the PD personality remains unclear and it is possible that personality differences noted in previous studies [5-9] represent changes that occurred at the same time or after the development of motor symptoms. Alternatively, the personality characteristics commonly associated with PD may represent longstanding traits and be detectable in early-adult life decades before initial motor symptoms. Previous studies suggest that premorbid personality characteristics may be associated with the risk of PD [5-10]. However, most of these studies utilized recall of subjective personality characteristics in early life, which may have been biased by the presence of the disease.

The objective of the present study was to determine to what extent activity- and lifestyle-based indicators of earlyadult life personality correlate with personality characteristics typically seen in PD patients after diagnosis. If PD personality characteristics emerge along with motor symptoms 
of the disease, the correlations between these characteristics and early-life activities and lifestyle might be expected to differ between individuals with PD and those without this disease. Conversely, if both cases and controls show correlations in the same direction and magnitude, it would suggest that these indicators of personality early in life represent stable personality characteristics, enabling them to be used as surrogate measures of early personality characteristics.

\section{Methods}

\section{Sample}

The Parkinson's Disease and Movement Disorders Center North Campus (PDMDC) at the University of South Florida (USF) is recognized as a Center of Excellence, serving over 5,000 patients in West Central Florida. Potential cases were identified through chart review of all patients who visited the PDMDC between January 1, 2007 and May 1, 2010. All cases whose charts indicated they met eligibility criteria were mailed recruitment materials. Potential controls were identified through a list of all patients age 50 - 80 years who visited the Family Practice Clinics at USF between January 1, 2007 and December 31, 2007. From this list, each individual was assigned a random number [11], generating a unique pseudorandom value between 0 and 1 for each entry. Recruitment materials were mailed to individuals in sequential order in batches of 50 until the end of the recruitment period (May 2010).

\section{Inclusion/exclusion criteria}

Subjects were deemed eligible for the study if they met the following criteria: 1) age 50 - 80 years, 2) no evidence of significant memory impairment, and 3) able to speak and read English. Cases also must have been diagnosed with PD within the past 10 years and had to fulfill UK Brain Bank Criteria [12]. We further required cases to have no atypical features of PD (pyramidal tract or cerebellar signs, apraxia, supranuclear gaze palsy, unresponsiveness to levodopa, prominent and early autonomic dysfunction, or history of exposure to toxic substances associated with parkinsonism), absence of a history of surgical interventions for PD and lack of severe motor fluctuations ( $>50 \%$ of the day with dyskinesia or "off" time).

PD is more prevalent in Caucasians than in Asians and Blacks $[13,14]$ and racial differences in several domains of the five-factor model (NEO FFI) have been reported [15, $16]$. Because of these potential differences and the underrepresentation of minorities in the PDMDC, the study was restricted to Caucasians, resulting in the exclusion of three Asians and five Blacks.

The protocol and questionnaires were approved by the
USF Institutional Review Board, and all subjects gave written informed consent.

\section{Procedures}

Potential participants were contacted by telephone 4 - 5 days after the initial mailing to screen and recruit them for the study. Five attempts were made to contact each potential subject including at least one week day, one evening and one weekend call.

\section{Exposure ascertainment}

Study assessments were completed in a private setting at the medical clinic. Trained interviewers used highly structured questionnaires to complete in-person assessments. Assessments included measures of current personality, early-adult life personality indicators and covariates. Names and scaling information for all personality variables are summarized in Table 1.

\section{Current personality measures}

\section{NEO FFI}

The NEO [14] identifies five broad dimensions of personality: openness, conscientiousness, extraversion, agreeableness and neuroticism (Table 1). Scores for these traits follow a continuum between the two extremes that define the trait, with a score of 1 representing the lower extreme and 5 representing the higher extreme.

\section{Temperament and character inventory (TCI)}

The TCI is based on Cloninger's psychobiological theory of personality and establishes differences between people with respect to seven dimensions of temperament and character [17]. The four temperament scales, described in Table 1, include novelty-seeking, harm-avoidance, reward dependence and persistence. The three character scales assess self-directedness, cooperativeness and self-transcendence. Each item is rated as true or false by the subject. Answers reflecting a quality associated with a particular character or trait contribute 1 point toward the subscale score for that character or trait (some items are reverse-scored). Higher scores on a domain indicate greater presence of the temperament or character quality.

Premorbid personality indicators: risk-taking and routinization

Indicators of premorbid personality included three questionnaires developed by members of the study team (KLS, ARB and JAM) asking about routinized lifestyles and risk-taking 
Table 1. Current Personality Measures and Early-Adult Life Personality Indicators

\begin{tabular}{|c|c|c|c|}
\hline Variable & Description & Instrument of origin & Score (range) \\
\hline Openness & $\begin{array}{l}\text { Inventive and curious (higher score) rather than } \\
\text { cautious (lower score) }\end{array}$ & NEO & $10-50$ \\
\hline Conscientiousness & $\begin{array}{l}\text { Efficient and organized (higher score) rather than easy- } \\
\text { going and careless (lower score) }\end{array}$ & NEO & $12-60$ \\
\hline Extraversion & $\begin{array}{l}\text { Outgoing and energetic (higher score) rather than shy } \\
\text { and reserved (lower score) }\end{array}$ & NEO & $12-60$ \\
\hline Agreeableness & $\begin{array}{l}\text { Friendly and compassionate (higher score) rather than } \\
\text { cold and unkind (lower score) }\end{array}$ & NEO & $12-60$ \\
\hline Neuroticism & $\begin{array}{l}\text { Sensitive and nervous (higher score) rather than secure } \\
\text { and confident (lower score) }\end{array}$ & NEO & $12-60$ \\
\hline Novelty-seeking & $\begin{array}{l}\text { Easily angered, curious, easily bored, impulsive, } \\
\text { extravagant and disorderly (higher scores indicate } \\
\text { greater presence of the temperament) }\end{array}$ & TCI & $0-20$ \\
\hline Harm-avoidance & $\begin{array}{l}\text { Exhibited as fear, inhibition of behavior in response } \\
\text { to punishment or non-reward, and pessimism (higher } \\
\text { scores indicate greater presence of the temperament) }\end{array}$ & TCI & $0-20$ \\
\hline Reward-dependence & $\begin{array}{l}\text { Attachment, sentimentality, social sensitivity and } \\
\text { dependence on approval by others (higher scores } \\
\text { indicate greater presence of the temperament) }\end{array}$ & TCI & $0-15$ \\
\hline Persistence & $\begin{array}{l}\text { Ambition, industriousness, determination and } \\
\text { perfectionism (higher scores indicate greater presence } \\
\text { of the temperament) }\end{array}$ & TCI & $0-5$ \\
\hline Self-directedness & $\begin{array}{l}\text { Responsible, reliable, resourceful, goal-oriented and } \\
\text { self-confident (higher scores indicate greater presence } \\
\text { of the character) }\end{array}$ & TCI & $0-25$ \\
\hline Cooperativeness & $\begin{array}{l}\text { Perception of oneself as part of society; empathetic, } \\
\text { tolerant and compassionate (higher scores indicate } \\
\text { greater presence of the character) }\end{array}$ & TCI & $0-25$ \\
\hline Self-transcendence & $\begin{array}{l}\text { Perception of oneself as part of the universe as a whole; } \\
\text { spiritual, unpretentious, humble and fulfilled (higher } \\
\text { scores indicate greater presence of the character) }\end{array}$ & TCI & $0-15$ \\
\hline Early-adult routinization & $\begin{array}{l}\text { Preference for regularity in daily activities and routines } \\
\text { ages } 20 \text { - } 35 \text { years }\end{array}$ & $\begin{array}{l}\text { Routinization } \\
\text { instrument } \\
\text { (Supplementary 1) }\end{array}$ & $0.10-0.56^{*}$ \\
\hline Early-adult activity risks & Engagement in risky activities ages $20-35$ years scores & $\begin{array}{l}\text { Risk taking } \\
\text { instruments } \\
\text { (Supplementary } 2 \text { and } \\
\text { Supplementary } 3 \text { ) }\end{array}$ & $0.65-3.77 *$ \\
\hline $\begin{array}{l}\text { Early-adult lifestyle } \\
\text { risks }\end{array}$ & $\begin{array}{l}\text { Engagement in risky behaviors (smoking cigarettes and } \\
\text { drinking alcohol) ages } 20 \text { - } 35 \text { years }\end{array}$ & $\begin{array}{l}\text { Smoking and drinking } \\
\text { histories (pack-years } \\
\text { and drink-years) }\end{array}$ & $0.53-3.08 *$ \\
\hline
\end{tabular}

${ }^{*}$ Range after standardization of component item scores and calculation of latent variable. 
Table 2. Routinization Factor Loadings (Based on Controls)

\begin{tabular}{|c|c|c|}
\hline Item & $\begin{array}{l}\text { Factor } 1 \\
\text { (routinization) }\end{array}$ & $\begin{array}{l}\text { Factor } 2 \text { (externally influenced } \\
\text { experiences) }\end{array}$ \\
\hline \multicolumn{3}{|l|}{ Average loadings (early-adult and current) } \\
\hline In general, I like(d) to do the same things each day. & 0.59 & 0.06 \\
\hline I like(d) to wake up and go to bed at the same time each day. & 0.55 & -0.12 \\
\hline I like(d) to eat my meals at the same time each day. & 0.72 & -0.15 \\
\hline I like(d) to try new or different foods. & 0.14 & 0.71 \\
\hline $\begin{array}{l}\text { I usually sit/sat in the same seat when doing certain activities } \\
\text { (for example, reading, watching TV, eating). }\end{array}$ & 0.65 & -0.12 \\
\hline $\begin{array}{l}\text { I usually put personal objects back in the same place each } \\
\text { time I use(d) them. }\end{array}$ & 0.40 & -0.27 \\
\hline I like(d) to plan my days out in advance. & 0.42 & -0.50 \\
\hline Other people think/thought I am/was "set in my ways." & 0.67 & -0.08 \\
\hline I think I am/was "set in my ways." & 0.74 & -0.12 \\
\hline I like(d) to meet new people. & 0.32 & 0.76 \\
\hline I like(d) to try new things that I have never done before. & 0.46 & 0.74 \\
\hline
\end{tabular}

behaviors.

\section{Routinization}

Early-adult routinization (Supplementary 1, www.neurores. org) asked subjects about the regularity of their meal times and preferences for doing the same activities each day. Subjects were given choices on a Likert scale (always, usually, sometimes, seldom or never) to indicate how well 13 statements described them between the ages of $20-35$ years. After completing this questionnaire, subjects were asked to report their current behaviors related to these activities. Responses were coded 0 - 4 with 0 assigned to the least routinized option and 4 assigned to the most routinized option (see score key in Supplementary 1, www.neurores.org). The total score for this instrument was obtained by summing the score for the 13 items; the minimum possible score was 0 (not routinized) and the maximum possible was 52 (highly routinized).

\section{Risky activities (RAs) questionnaire}

The RA questionnaire assessed participation in 10 RAs
(Supplementary 2, www.neurores.org), including whether the subject had ever parachuted out of an airplane, ridden a motorcycle or a roller coaster, swum far from shore, gambled for large or small sums of money, parasailed, skied, or flew in a small plane. If a subject indicated they had participated in an activity, they were asked their age at the time of participation ("before 35", "after 35" and "both ages") and if they enjoyed the activity ("not at all", "sort of", "moderately" and "very much"). In order to assess the desire to engage in activities in the absence of the opportunity to actually have engaged in it, subjects were asked if they ever wanted to do each activity in which they had not participated. This questionnaire resulted in two scores representing risk-taking and sensation-seeking. To obtain the risk-taking score, one point was scored for each activity in which the subject participated for each time period or in which the subject did not participate in, but wanted to. The minimum possible risk-taking score was 0 points (no RAs) and the maximum possible risktaking score was 10 points (10 RAs). The sensation-seeking score was based on the greatest level of enjoyment reported for any item on the questionnaire and ranged from 0 (no RAs or activities were enjoyed "not at all") to 3 (enjoyed at least one activity "very much"). 

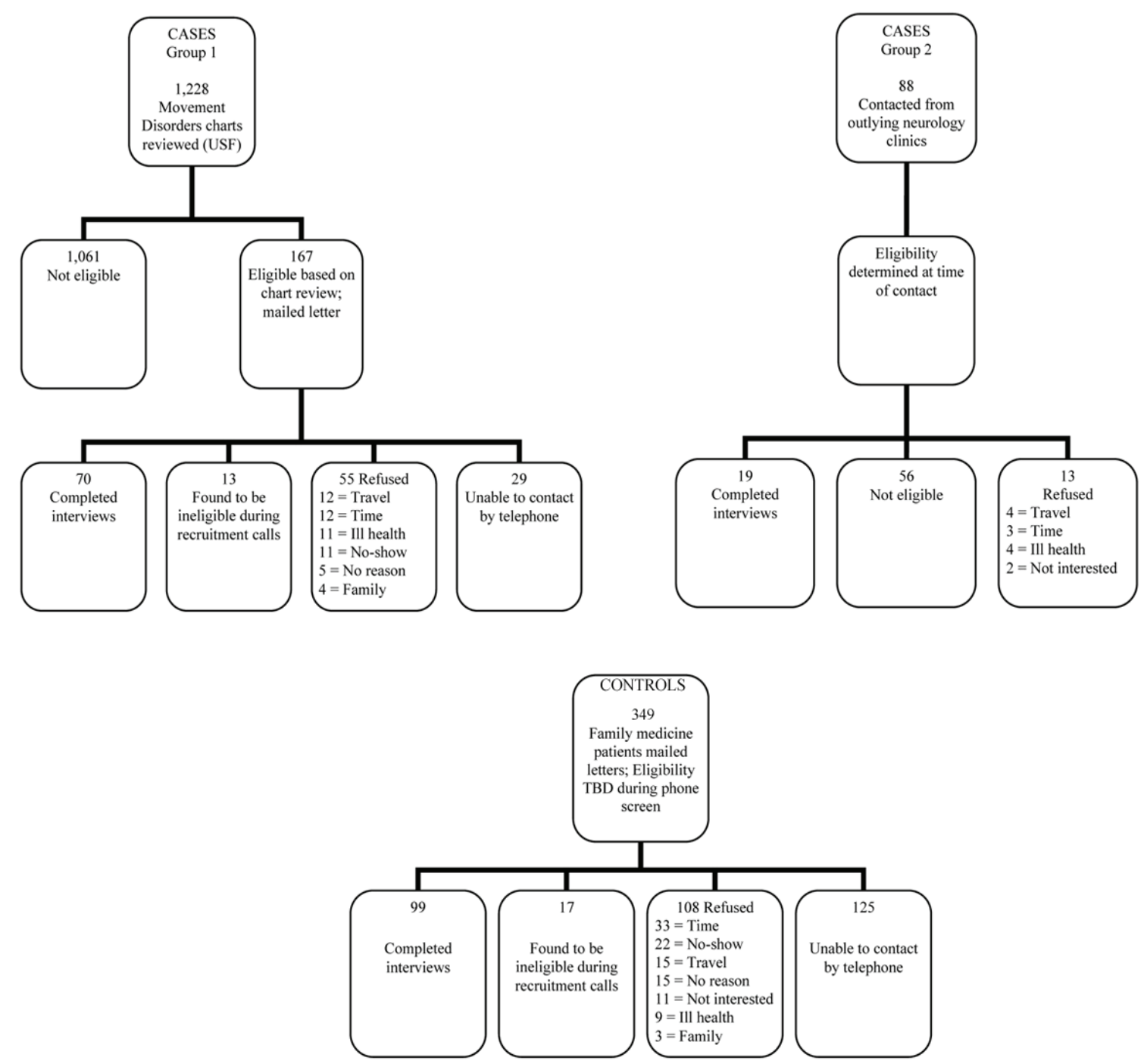

Figure 1. Participation among cases and controls.

\section{Risky behavior (RB) questionnaire}

Subjects were asked to select the most accurate description of themselves from a group of statements related to five specific situations or behaviors: speeding when driving, flying in airplanes, getting lost in familiar and unfamiliar places, being in a high place, and wearing seatbelts in addition to a general summation of their enjoyment of risky situations (Supplementary 3, www.neurores.org). Response choices included options without risk ( 0 points) as well as $2-3$ options with increasing amounts of risk. Greater levels of risk scored more highly. Points for these six questions were summed to obtain the total score for this instrument with possible scores ranging from 0 points (behaviors with no risk or minimal risk) to 15 points (most risky behaviors).

\section{Other covariates}

Other variables obtained included age at time of assessment; sex; years of education; smoking history including if subjects ever smoked cigarettes on a regular basis, the usual number of cigarettes smoked per day and the age smoking began and ended; and history of alcohol consumption including if subjects ever drank alcohol on a regular basis (defined as routinely drinking one or more alcoholic beverages per month), the number of servings of wine, beer and liquor consumed and the age each type of alcohol consumption started and ended. Smoking and alcohol data were converted into packyears and drink-years to calculate total lifetime exposures. The age and sex of eligible cases and controls who refused study participation were abstracted from medical records. 
Table 3. Comparison of Participants and Refusals

\begin{tabular}{lllll}
\hline & & $\begin{array}{l}\text { Participants } \\
\text { (cases n= 89; controls } \\
\mathbf{n = 9 9 )}\end{array}$ & $\begin{array}{l}\text { Refusals } \\
\text { (cases n =68; controls } \\
\mathbf{n = 1 0 8})\end{array}$ & P value \\
\hline \multirow{2}{*}{ Age, in years } & & & \\
& Cases & $68.47 \pm 8.00$ & $68.46 \pm 7.65$ & 0.99 \\
Sex (\% male) & Controls & $67.31 \pm 6.96$ & $66.64 \pm 7.50$ & 0.50 \\
& Cases & 65.17 & 55.88 & 0.24 \\
& Controls & 44.44 & 45.37 & 0.89 \\
\hline
\end{tabular}

aMean \pm SD (range).

\section{Statistical methods}

\section{Descriptive statistics}

Descriptive statistics were obtained for demographic characteristics and independent variables, including means and standard deviations for continuous variables and frequency distributions for categorical variables. T-tests were used to compare cases and controls for continuous variables (age, years of education, pack-years of smoking and alcohol consumption) and Chi-square for categorical variables (sex). Differences between participants and those who refused participation were examined using $t$-tests for continuous variables and contingency table analysis (Chi-square) for categorical variables.

\section{Exploratory factor analysis of routinization instrument}

To evaluate the structure of the routinization instrument, a principal components factor analysis was conducted among the controls for two versions (one applicable to ages 20 35; the other (not shown) applicable to preferences at the time the questionnaire was administered). For both versions, two factors were retained with eigenvalues greater than 1.0 (Table 2). One of these corresponded to a desire to maintain a routine and was labeled as "routinization." The other corresponded to a desire for experiences influenced by external factors and was labeled "externally influenced experiences." Weighted item scores for these two factors were summed to obtain the subject's scores for each factor. Two items from the original instrument were not retained based on factor analysis. "I like to watch new shows or films on television" was dropped because it did not load on either of the retained components and did not fit conceptually with the other items in either component. When factor loadings among cases and controls were examined separately, "I like when things happen spontaneously" loaded on different components for cases and controls and was not retained. Cronbach's alpha for this scale was 0.74 .

\section{Construction of latent variables for personality}

Principal components factor analysis was conducted among controls with scores for routinization, externally influenced experiences, sensation-seeking, RAs, RB, smoking and alcohol consumption (in pack-years and drink-years). These analyses were performed on data for ages 20 - 35 and the current period and factors with eigenvalues of 1.0 or higher were identified. The item representing "externally influenced experiences" was not retained because it did not load on any of the retained components and did not fit conceptually with the other items in each component. A varimax rotation was performed after the item selection was finalized in order to reduce collinearity.

Separate data for ages 20 - 35 and the current period resulted in two sets of loadings. Although the loadings for each period were in the same direction and general magnitude, they were not identical and the loadings for ages 20 - 35 and the current period were averaged for each item. The averaged loading was used to weight the standardized value of each item. The weighted item scores were then summed to obtain the value for each latent variable which was used in subsequent analyses.

\section{Potential confounders}

Age [18-20] and sex [18, 21] are risk factors for PD, and their associations with personality were therefore tested. Education also was considered as a potential confounder.

\section{Logistic regression analysis}

The association of current personality items with the risk of PD was assessed through logistic regression analyses adjusted for age, sex and education. Separate models were constructed for each personality characteristic. $\mathrm{P}$ values of less 
than 0.05 (two-sided probability) were interpreted as being statistically significant.

Correlation of premorbid personality indicators with current personality characteristics

Pearson correlation coefficients were calculated to examine the association of early-adult life personality indicators with current personality traits in cases and controls separately, with the effects of age, sex and education partialled out. All analyses used SAS version 9.2 [22].

\section{Results}

Figure 1 summarizes participation among cases and controls. For cases, 1,228 charts were reviewed; 1,061 were considered ineligible and 167 were eligible and mailed recruitment materials. The first reason for ineligibility was noted and included diagnosis other than PD $(\mathrm{n}=568)$, age less than 50 years $(n=154)$, age greater than 80 years $(n=114)$, atypical parkinsonism $(\mathrm{n}=75)$, PD diagnosed more than 10 years earlier $(n=65)$, surgical intervention for PD $(n=33)$, cognitive impairment $(\mathrm{n}=29)$, severe motor fluctuations $(\mathrm{n}=8)$, race $(\mathrm{n}=8)$, unable to complete study assessments $(\mathrm{n}=2$ who did not speak English), departed study area $(\mathrm{n}=1)$ and deceased $(n=4)$. Telephone calls were made to these 167 potential cases and 138 were successfully contacted. Upon further assessment of eligibility by telephone, 13 cases were found to be ineligible (atypical parkinsonism $(\mathrm{n}=1)$, unable to speak English $(n=2)$, cognitive impairment $(n=2)$, deceased $(\mathrm{n}=1)$, PD diagnosed more than 10 years ago ( $=3)$, diagnosis other than PD $(\mathrm{n}=1)$, surgical intervention for PD $(n=2)$ and departed study area $(n=1))$. Fifty-five of the remaining 125 potential cases refused participation and 70 completed study interviews. The participation rate among eligible cases was 70/125 (56\%).

In addition to the cases recruited from the PDMDC, cases were recruited from two outlying neurology clinics in order to increase the sample size. Eighty-eight patients from these clinics were contacted; 56 were ineligible due to diagnosis other than PD $(n=11)$, age less than 50 years $(n=1)$, age greater than 80 years $(n=20)$, atypical parkinsonism ( $n$ $=5)$, PD diagnosed more than 10 years earlier $(n=4)$, surgical intervention for PD $(n=10)$, cognitive impairment $(n=$ $1)$, severe motor fluctuations $(n=1)$, race $(n=2)$ and unable to complete study assessments ( $\mathrm{n}=1$ who was blind). Thirteen potential subjects from these sites refused participation and 19 participated.

The computer-generated list of eligible controls included 5,158 individuals. Letters were mailed to 349 potential controls and 224 were successfully contacted by telephone. Upon further assessment of eligibility, 17 controls were found to be ineligible (inability to speak English $(n=6)$, de- 
Table 5. Early-Adult Personality Item Factor Loadings (Based on Controls)

\begin{tabular}{llll}
\hline Item & $\begin{array}{l}\text { Factor 1 } \\
\text { (activity } \\
\text { risks) }\end{array}$ & $\begin{array}{l}\text { Factor 2 } \\
\text { (lifestyle } \\
\text { risks) }\end{array}$ & $\begin{array}{l}\text { Factor 3 } \\
\text { (routinization) }\end{array}$ \\
\hline $\begin{array}{l}\text { Average loadings (early-adult and current) } \\
\text { Routinization score }\end{array}$ & -0.03 & 0.04 & 0.93 \\
$\quad \begin{array}{l}\text { Risky behavior score } \\
\text { Risky activities: risk taking score }\end{array}$ & 0.55 & 0.05 & -0.53 \\
$\quad$ Risky activities: sensation-seeking score & 0.81 & 0.12 & -0.02 \\
$\quad$ Smoking (pack-years) & 0.81 & -0.02 & -0.07 \\
Alcohol consumption (drink-years) & 0.06 & 0.78 & -0.13 \\
\hline
\end{tabular}

ceased $(n=5)$, race $(n=4)$, atypical parkinsonism $(n=1)$ and cognitive impairment $(\mathrm{n}=1))$. One hundred and eight of the remaining 207 potential cases refused participation and 99 completed study interviews. The participation rate among eligible controls was 99/207 (48\%). Demographic characteristics of individuals who participated in the study were compared to those who refused participation (Table 3). For both cases and controls, there were no significant differences in age or sex between those who participated and those who refused.

Demographic and current personality characteristics of the study sample are shown in Table 4. There was a higher proportion of men among cases (65\%) compared with controls $(44 \%, \mathrm{P}=0.005)$. In addition, cases had fewer total years of education compared with controls $(14.81 \pm 3.10$ years compared with $16.26 \pm 3.54$ years, $\mathrm{P}=0.003)$. Eversmoking $(\mathrm{OR}=0.88(95 \% \mathrm{CI} 0.50-1.57))$ and ever-drinking alcohol $(\mathrm{OR}=1.30(95 \%$ CI $0.60-2.83))$ did not differ sig-

Table 6. Association of Current Personality Traits With PD (OR (95\% CI))

\begin{tabular}{lll}
\hline Effect & Unadjusted model & Adjusted model $^{\mathrm{a}}$ \\
\hline Neuroticism $^{\mathrm{b}}$ & $1.04(1.00-1.09)$ & $1.05(1.00-1.11)^{*}$ \\
Extraversion $^{\mathrm{b}}$ & $0.99(0.94-1.04)$ & $1.00(0.95-1.06)$ \\
Openness $^{\mathrm{b}}$ & $0.94(0.89-0.98)^{*}$ & $0.98(0.91-1.05)$ \\
Agreeableness $^{\mathrm{b}}$ & $0.99(0.93-1.05)$ & $1.03(0.96-1.10)$ \\
Conscientiousness $^{\mathrm{b}}$ & $0.96(0.91-1.01)$ & $0.96(0.91-1.01)$ \\
Novelty-seeking $^{\mathrm{c}}$ & $1.08(0.98-1.19)$ & $1.09(0.99-1.21)$ \\
Harm-avoidance $^{\mathrm{c}}$ & $1.05(0.99-1.12)$ & $1.07(1.00-1.15)^{*}$ \\
Reward dependence $^{\mathrm{c}}$ & $0.95(0.86-1.05)$ & $0.96(0.86-1.07)$ \\
Persistence $^{\mathrm{c}}$ & $1.07(0.88-1.29)$ & $1.09(0.88-1.34)$ \\
Self-directiveness $^{\mathrm{c}}$ & $0.91(0.83-0.99)^{*}$ & $0.92(0.84-1.01)$ \\
Cooperativeness $^{\mathrm{c}}$ & $0.86(0.76-0.98)$ & $0.89(0.78-1.02)$ \\
Self-transcendence $^{\mathrm{c}}$ & $0.97(0.91-1.05)$ & $0.96(0.89-1.04)$ \\
\hline
\end{tabular}

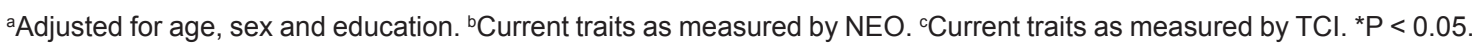


Table 7. Partial Correlation Coefficients for Early-Adult Indicators and Current Personality Measures

\begin{tabular}{|c|c|c|c|c|}
\hline \multicolumn{2}{|c|}{ Current personality measure } & \multirow{2}{*}{$\begin{array}{l}\text { Activity risks } \dagger \\
-0.33^{*}\end{array}$} & \multirow{2}{*}{$\begin{array}{l}\text { Lifestyle risks } \dagger \\
-0.11\end{array}$} & \multirow{2}{*}{$\begin{array}{l}\text { Routinization } \dagger \\
0.33^{*}\end{array}$} \\
\hline Neuroticism & Cases & & & \\
\hline & Controls & -0.15 & -0.07 & $0.26^{*}$ \\
\hline \multirow[t]{2}{*}{ Extraversion } & Cases & 0.24 & -0.03 & $-0.33^{*}$ \\
\hline & Controls & $0.37 *$ & 0.02 & $-0.33^{*}$ \\
\hline \multirow[t]{2}{*}{ Openness } & Cases & -0.02 & -0.16 & -0.01 \\
\hline & Controls & $0.26^{*}$ & 0.08 & $-0.33 *$ \\
\hline \multirow[t]{2}{*}{ Agreeableness } & Cases & -0.09 & -0.06 & 0.19 \\
\hline & Controls & -0.15 & -0.20 & -0.01 \\
\hline \multirow[t]{2}{*}{ Conscientiousness } & Cases & 0.03 & 0.27 & 0.15 \\
\hline & Controls & 0.20 & 0.03 & -0.02 \\
\hline \multirow[t]{2}{*}{ Novelty-seeking } & Cases & 0.23 & 0.07 & $-0.33 *$ \\
\hline & Controls & 0.21 & 0.08 & $-0.34 *$ \\
\hline \multirow[t]{2}{*}{ Harm-avoidance } & Cases & $-0.47 *$ & -0.15 & $0.47^{*}$ \\
\hline & Controls & $-0.42 *$ & -0.08 & $0.45^{*}$ \\
\hline \multirow[t]{2}{*}{ Reward dependence } & Cases & -0.25 & -0.21 & 0.14 \\
\hline & Controls & 0.12 & -0.19 & 0.03 \\
\hline \multirow[t]{2}{*}{ Persistence } & Cases & -0.01 & 0.02 & 0.09 \\
\hline & Controls & 0.07 & 0.07 & -0.06 \\
\hline \multirow[t]{2}{*}{ Self-directiveness } & Cases & 0.17 & 0.11 & -0.01 \\
\hline & Controls & 0.14 & 0.15 & 0.03 \\
\hline \multirow[t]{2}{*}{ Cooperativeness } & Cases & -0.12 & 0.17 & 0.12 \\
\hline & Controls & 0.11 & -0.11 & -0.13 \\
\hline \multirow[t]{2}{*}{ Self-transcendence } & Cases & -0.04 & 0.05 & -0.04 \\
\hline & Controls & 0.04 & -0.22 & -0.02 \\
\hline
\end{tabular}

†Adjusted for age, sex and education. ${ }^{*} \mathrm{P}<0.05$.

nificantly between cases and controls.

\section{Factor analysis of early-adult life personality indicators}

Three factors were retained in the factor analysis of RAs, RBs, routinization, sensation-seeking, lifetime smoking and alcohol consumption (Table 5). The grouping of items into the three factors represented three latent constructs: routinization, lifestyle risks (smoking and alcohol consumption) and activity risks (RAs and RBs).

\section{Current personality}

Personality dimensions assessed by the NEO FFI demon- strated that higher levels of neuroticism were associated with having PD (OR $=1.05$ (95\% CI $1.00-1.11)$ ) adjusting for age, sex and education (Table 6). PD was also associated with higher levels of harm-avoidance (OR $=1.07(95 \% \mathrm{CI}$ $1.00-1.15)$ ). There were no significant associations between $\mathrm{PD}$ and other NEO or TCI measures.

Association of early personality indicators and current personality

Consistent patterns of significant correlations were observed among both cases and controls for early-adult life routinization with current measures of neuroticism (cases: $\mathrm{r}=0.33, \mathrm{P}$ $=0.01$; controls: $\mathrm{r}=0.26, \mathrm{P}=0.04$ ), extraversion (cases: $\mathrm{r}=$ 
-0.33, $\mathrm{P}=0.01$; controls: $\mathrm{r}=-0.33, \mathrm{P}=0.04)$, novelty-seeking (cases: $\mathrm{r}=-0.33, \mathrm{P}=0.01$; controls: $\mathrm{r}=-0.34, \mathrm{P}=0.007$ ), harm-avoidance (cases: $\mathrm{r}=0.47, \mathrm{P}=0.0003$; controls: $\mathrm{r}=$ $0.45, \mathrm{P}=0.0002$ ) and for the association of early-adult life activity risks with harm-avoidance (cases: $\mathrm{r}=-0.47, \mathrm{P}=$ 0.0004; controls: $\mathrm{r}=-0.42, \mathrm{P}=0.0006$ ) (Table 7).

\section{Discussion}

We found that PD cases had higher current levels of neuroticism and harm-avoidance than controls. Current personality characteristics were associated with indicators of early-adult personality, including taking activity risks and routinization in both cases and controls.

Case-control studies have found differences in current personality characteristics, including reduced sensationseeking [23], reduced novelty-seeking [24, 25] and higher harm-avoidance $[24,26]$ in cases with PD compared to normal [23, 24] and medical [25, 26] controls. Fujii et al [24] found that the mean novelty-seeking score among cases was significantly reduced compared with controls (mean $\pm \mathrm{SD}=$ $12.36 \pm 3.02$ among cases and $13.71 \pm 3.15$ among controls, $\mathrm{P}<0.05)$ while harm-avoidance was significantly greater among cases $($ mean $=19.94 \pm 5.14)$ compared with controls $($ mean $=15.73 \pm 6.49)(\mathrm{P}<0.001)$. However, cases were administered the test via interview, while controls completed a paper version of the questionnaire; this difference in mode of administration could have biased the results away from the null. In our study, novelty-seeking was not associated with PD. The different findings in previous studies of reduced novelty-seeking among individuals with $\operatorname{PD}[6,25]$ and our null finding may be attributable to a change in patterns of treatment for PD over time. Both of the previous studies were conducted prior to the approval of the dopamine agonists (DAs) pramipexole and ropinirole for the treatment of PD in 1997. Since that time, DAs have become first-line treatments for PD $[27,28]$. DAs have been shown to significantly increase novelty-seeking in previously unmedicated patients with PD, while harm-avoidance remained unchanged [29]. In the present study, 83 cases $(93 \%)$ were taking DAs for PD with $46 \%$ taking ropinirole or pramipexole. None of the controls reported taking either medication.

Findings similar to our observations of increased neuroticism and harm-avoidance have been reported previously. A historical cohort study of 7,216 subjects in Rochester, Minnesota evaluated measures from the Minnesota Multiphasic Personality Inventory (MMPI) and found that increased neuroticism as a younger adult was associated with higher PD risk $(\mathrm{HR}=1.54 ; 95 \%$ CI 1.10 - 2.16) [30]. In a study of 122 young, unmedicated patients with PD, Jacobs et al [31] reported higher levels of harm-avoidance (mean $\pm \mathrm{SD}=17.8$ $\pm 5.7)$ compared with age- and sex-matched controls (12.1 $\pm 4.9)$.
Dopaminergic activity has been reported as the primary influence on harm-avoidance [32]; harm-avoidance has been shown to correlate with decreased ${ }^{18} \mathrm{~F}$-dopa uptake in the right caudate nucleus $(\mathrm{r}=0.53, \mathrm{P}=0.04)$ [26]. Differences in novelty-seeking and harm-avoidance in individuals with PD compared with controls have been reported to depend on the brain hemisphere where dopamine loss was most pronounced [33] with reduced novelty-seeking associated with left-hemisphere dopamine deficiency and increased harmavoidance associated with right-hemisphere dopamine deficiency.

Personality traits are highly stable during adulthood [34-36], although there is evidence for a "maturation effect" [37]. We found a stable association between activity risks in early-adult life and harm-avoidance as well as between early routinization preference and novelty-seeking, both of which may be related to dopaminergic function [38]. This stability was present not only among controls, but also among cases, which supports the hypothesis that behaviors associated with the PD personality may exist many years before the presentation of motor symptoms.

This study had several strengths. The assessments were unique in that they used activities and lifestyle patterns as retrospective indicators of personality traits. Previous studies of premorbid personality traits have employed subjective assessment of personality traits that may be more likely to be affected by recall bias. Another strength was the selection of medical controls, which reduces the potential for selection bias related to factors associated with the probability of seeking medical care (such as socioeconomic status) and of being diagnosed with PD if symptoms are present.

Our study is limited by the retrospective assessment of early-adult life indicators related to personality. The possibility that recall of activities, behaviors and preferences in early-adult life may be influenced by current personality cannot be excluded. However, the fact that similar correlations were seen among both cases and controls suggests that the presence of PD symptoms is likely not responsible for the associations found.

\section{Disclosure}

No disclosures to report.

\section{References}

1. Camp C. Paralysis agitans, multiple sclerosis and their treatment. In: Jelliffe SE, White WA, Kimpton H, eds. Modern Treatment of Nervous and Mental Disease. Vol. 2. Philadelphia: Lea \& Febiger; 1913.

2. Menza M. The personality associated with Parkinson's 
disease. Curr Psychiatry Rep. 2000;2(5):421-426.

3. Hornykiewicz O. Dopamine (3-hydroxytyramine) and brain function. Pharmacol Rev. 1966;18(2):925-964.

4. Depue RA, Luciana M, Arbisi P, Collins P, Leon A. Dopamine and the structure of personality: relation of agonist-induced dopamine activity to positive emotionality. J Pers Soc Psychol. 1994;67(3):485-498.

5. Heberlein I, Ludin HP, Scholz J, Vieregge P. Personality, depression, and premorbid lifestyle in twin pairs discordant for Parkinson's disease. J Neurol Neurosurg Psychiatry. 1998;64(2):262-266.

6. Hubble JP, Venkatesh R, Hassanein RE, Gray C, Koller WC. Personality and depression in Parkinson's disease. J Nerv Ment Dis. 1993;181(11):657-662.

7. Ward CD, Duvoisin RC, Ince SE, Nutt JD, Eldridge R, Calne DB, Dambrosia J. Parkinson's disease in twins. Adv Neurol. 1984;40:341-344.

8. Eatough VM, Kempster PA, Stern GM, Lees AJ. Premorbid personality and idiopathic Parkinson's disease. Adv Neurol. 1990;53:335-337.

9. Poewe W, Gerstenbrand F, Ransmayr G, Plorer S. Premorbid personality of Parkinson patients. J Neural Transm Suppl. 1983;19:215-224.

10. Arabia G, Grossardt BR, Colligan RC, Bower JH, Maraganore DM, Ahlskog JE, Geda YE, et al. Novelty seeking and introversion do not predict the long-term risk of Parkinson disease. Neurology. 2010;75(4):349-357.

11. Microsoft. Microsoft Excel. Redmond, Washington: Microsoft; 2003.

12. Gibb WR, Lees AJ. A comparison of clinical and pathological features of young- and old-onset Parkinson's disease. Neurology. 1988;38(9):1402-1406.

13. Van Den Eeden SK, Tanner CM, Bernstein AL, Fross RD, Leimpeter A, Bloch DA, Nelson LM. Incidence of Parkinson's disease: variation by age, gender, and race/ ethnicity. Am J Epidemiol. 2003;157(11):1015-1022.

14. Tanner CM, Goldman SM. Epidemiology of Parkinson's disease. Neurol Clin. 1996;14(2):317-335.

15. Jonassaint CR, Boyle SH, Kuhn CM, Siegler IC, Copeland WE, Williams R. Personality and inflammation: the protective effect of openness to experience. Ethn Dis. 2010;20(1):11-14.

16. Savla J. DA, Costa P, Whitfield K. Replicating the NEOPI-R factor structure in African-American older adults. Pers Individ Dif. 2007;43:1279-1288.

17. Cloninger CR. A unified biosocial theory of personality and its role in the development of anxiety states. Psychiatr Dev. 1986;4(3):167-226.

18. Mayeux R, Denaro J, Hemenegildo N, Marder K, Tang MX, Cote LJ, Stern Y. A population-based investigation of Parkinson's disease with and without dementia. Relationship to age and gender. Arch Neurol. 1992;49(5):492497.

19. Kurland LT. Descriptive epidemiology of selected neu- rologic and myopathic disorders with particular reference to a survey in Rochester, Minnesota. J Chronic Dis. 1958;8(4):378-418.

20. Mutch WJ, Dingwall-Fordyce I, Downie AW, Paterson JG, Roy SK. Parkinson's disease in a Scottish city. Br Med J (Clin Res Ed). 1986;292(6519):534-536.

21. Mayeux R, Marder K, Cote LJ, Denaro J, Hemenegildo N, Mejia H, Tang MX, et al. The frequency of idiopathic Parkinson's disease by age, ethnic group, and sex in northern Manhattan, 1988-1993. Am J Epidemiol. 1995;142(8):820-827.

22. SAS 9.2. Cary, NC: SAS Institute Inc. 2008.

23. Evans AH, Lawrence AD, Potts J, MacGregor L, Katzenschlager R, Shaw K, Zijlmans J, et al. Relationship between impulsive sensation seeking traits, smoking, alcohol and caffeine intake, and Parkinson's disease. J Neurol Neurosurg Psychiatry. 2006;77(3):317-321.

24. Fujii C, Harada S, Ohkoshi N, Hayashi A, Yoshizawa K. Cross-cultural traits for personality of patients with Parkinson's disease in Japan. Am J Med Genet. 2000;96(1):1-3.

25. Menza MA, Golbe LI, Cody RA, Forman NE. Dopamine-related personality traits in Parkinson's disease. Neurology. 1993;43(3 Pt 1):505-508.

26. Kaasinen V, Nurmi E, Bergman J, Eskola O, Solin O, Sonninen P, Rinne JO. Personality traits and brain dopaminergic function in Parkinson's disease. Proc Natl Acad Sci U S A. 2001;98(23):13272-13277.

27. Olanow CW, Watts RL, Koller WC. An algorithm (decision tree) for the management of Parkinson's disease (2001): treatment guidelines. Neurology. 2001;56(11 Suppl 5):S1-S88.

28. Miyasaki JM, Martin W, Suchowersky O, Weiner WJ, Lang AE. Practice parameter: initiation of treatment for Parkinson's disease: an evidence-based review: report of the Quality Standards Subcommittee of the American Academy of Neurology. Neurology. 2002;58(1):11-17.

29. Bodi N, Keri S, Nagy H, Moustafa A, Myers CE, Daw $\mathrm{N}$, Dibo G, et al. Reward-learning and the novelty-seeking personality: a between- and within-subjects study of the effects of dopamine agonists on young Parkinson's patients. Brain. 2009;132(Pt 9):2385-2395.

30. Bower JH, GB, Maraganore DM, Ahlskog JE, de Andrade M, Rocca WA. The Mayo Clinic Cohort Study of Personality and Aging: Results for Parkinson's disease. Neurology. 2005;64(Suppl 1):A282-A283.

31. Jacobs H, Heberlein I, Vieregge A, Vieregge P. Personality traits in young patients with Parkinson's disease. Acta Neurol Scand. 2001;103(2):82-87.

32. Yasuno F, Suhara T, Sudo Y, Yamamoto M, Inoue M, Okubo Y, Suzuki K. Relation among dopamine D(2) receptor binding, obesity and personality in normal human subjects. Neurosci Lett. 2001;300(1):59-61.

33. Tomer R, Aharon-Peretz J. Novelty seeking and harm 
avoidance in Parkinson's disease: effects of asymmetric dopamine deficiency. J Neurol Neurosurg Psychiatry. 2004;75(7):972-975.

34. McCrae RR, Costa PT, Jr. Personality in Adulthood. New York: Guildford; 1990.

35. McCrae RR, Costa PT, Jr., Pedroso de Lima M, Simoes A, Ostendorf F, Angleitner A, Marusic I, et al. Age differences in personality across the adult life span: parallels in five cultures. Dev Psychol. 1999;35(2):466-477.

36. Costa PT, Jr., McCrae RR. Longitudinal stability of adult personality. In: Hogan RJ, Briggs S, eds. Handbook of Personality Psychology. New York: Academic Press; 1990:269-290.

37. Srivastava S, John OP, Gosling SD, Potter J. Development of personality in early and middle adulthood: set like plaster or persistent change? J Pers Soc Psychol. 2003;84(5):1041-1053.

38. Cloninger CR. A systematic method for clinical description and classification of personality variants. A proposal. Arch Gen Psychiatry. 1987;44(6):573-588. 